\title{
Marine Dissolved Organic Matter and the Carbon Cycle
}

\author{
Dennis A. Hansell \\ University of Miami - Miami, Florida USA
}

\author{
Craig A. Carlson \\ University of California . Santa Barbara, California USA
}

Some of our greatest advances in understanding the structure and functioning of natural systems occur when newly developed methods unlock scientific doors. Sometimes these gateways have been barred because of methodological constraints, sometimes because we have lacked reasons to seek them. When scientific necessity and methodology converge, advances in knowledge can be extraordinary. During the Joint Global Ocean Flux Study (JGOFS), such a convergence led to remarkable advances in our understanding of the role of Dissolved Organic Matter (DOM) in the ocean carbon cycle.

Designed to improve our knowledge of the marine carbon cycle, JGOFS depended upon focused studies of the major bioreactive pools of carbon and other elements in the ocean and, as a prerequisite, reliable and accurate methods of measuring these pools. The largest and best understood pool of reactive carbon in the global ocean is Dissolved Inorganic Carbon (DIC), which contains roughly $38,000 \times 10^{15} \mathrm{~g} \mathrm{C}$ (see Feely et al., this volume). We focus in this article on the global reservoir of DOM in the ocean, which contains roughly $685 \times 10^{15} \mathrm{~g} \mathrm{C}$, the second largest pool and the least understood at the beginning of JGOFS. DOM contains many biochemically identifiable classes of compounds such as sugars or amino acids, as well as fractions that are more coarsely classified, such as humics. As we consider the cycling of carbon through DOM, it is conceptually useful to isolate the DOM carbon, the fraction scientists term Dissolved Organic Carbon (DOC).

What role does DOM have in the cycling of marine carbon? Numerous publications prior to JGOFS provided insights on how to address this question. Several suggested that the DOM pool is largely old and refractory and thus unavailable for biological consumption. If this characterization is accurate, DOM does not play a central role as a highly reactive reservoir for carbon and could be viewed as unimportant to carbon fluxes and thus to concentrated study in JGOFS. If this characterization is inaccurate or incomplete, DOM requires serious study.

Seminal papers published during the 1980s challenged our long-held views on the role of DOM in the cycling of the major elements in the ocean (Suzuki et al., 1985; Sugimura and Suzuki, 1988). The then generally accepted and long-held view, as described in Williams and Druffel (1988), was that the biological pump functions primarily through the sinking of biogenic particles. In contrast, results of the experiments of suggested by Sugimura and Suzuki (1988) and Suzuki et al. (1985) suggested that concentrations of DOM were two to four times greater than previously thought, and also that DOC was centrally important to the functioning of the oceanic biological pump. These findings stimulated both alarm and excitement. If true, they would force us to change our long-held belief, and hence were a major reason why JGOFS concentrated on DOM.

In part because of the impetus provided by JGOFS and its core questions, a group of scientists was drafted to test the findings of these provocative papers. The main problem was quickly apparent; the various analytical methods used to measure DOC-including high temperature oxidation, ultra-violet irradiation and persulfate oxidation-were unreliable, and often did not agree. Many new analysts joined the fray, few of whom had experience with DOM measurements. Thus the early analytical results varied widely. Some analysts claimed to find their results in full confirmation of the high DOM concentrations reported by Suzuki et al. (1985) and Sugimura and Suzuki (1988). Those who could not replicate the new measurements had to consider the possibility that their analytical abilities were inferior to those who had verified the high DOC concentrations.

Continuing disagreement among results required scientists to step back from applying them in field studies. Instead a series of intercomparison exercises were organized that proved invaluable for evaluating the methods, however vexingly slow. While investigators interested in DOC were wrestling with questions of methodology, U.S. JGOFS field studies proceeded without reliable techniques for measuring one of the largest carbon pools in the ocean. The pressure to solve the analytical uncertainties increased.

While the full story of how the DOC methods were 


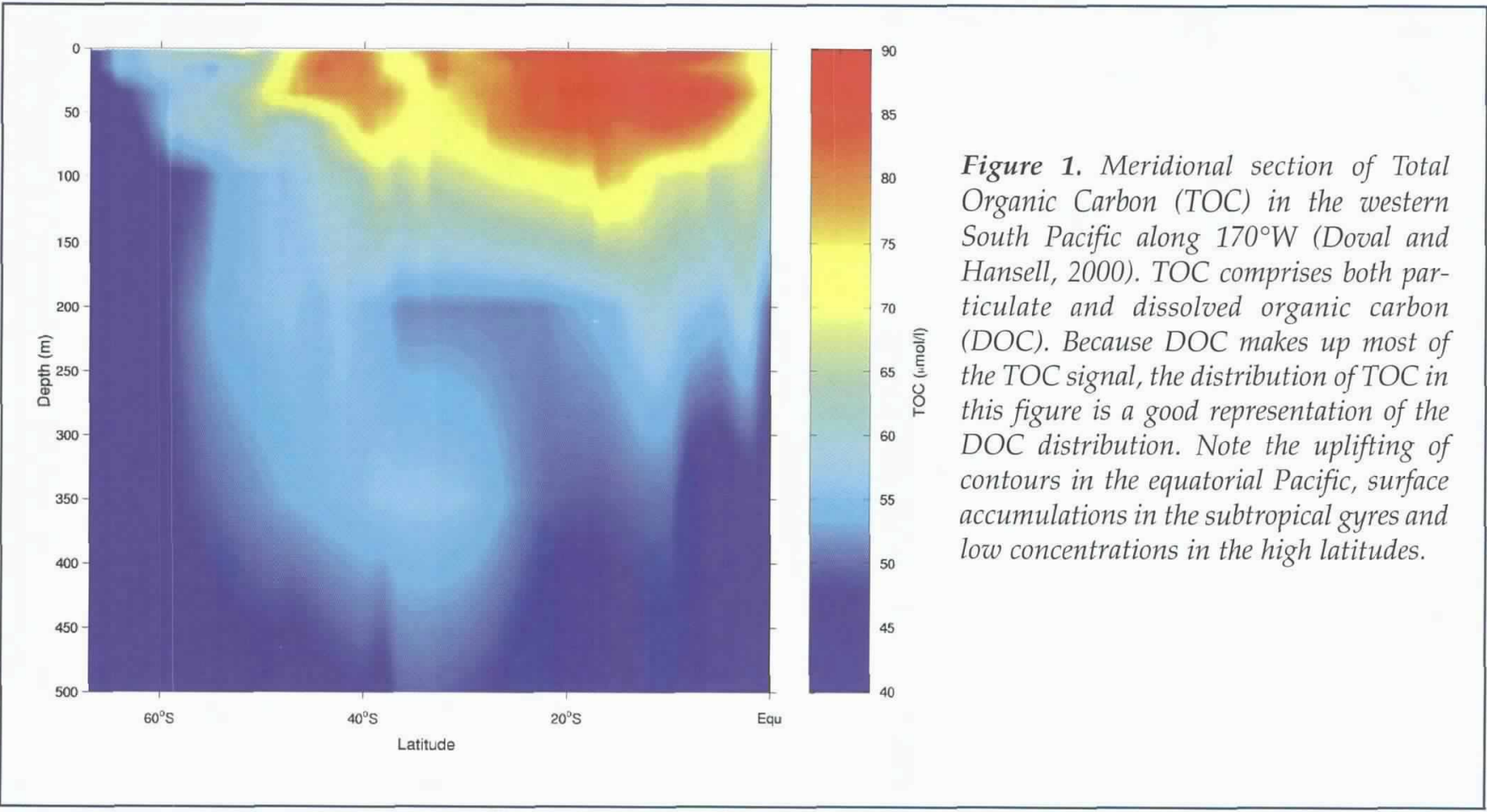

evaluated is too long for full treatment here, we will provide brief historical highlights. For more details on methodology and history, refer to the forthcoming book entitled Biogeochemistry of Marine Dissolved Organic Matter (Academic Press), edited by D.A. Hansell and C.A. Carlson.

Community-wide DOC method intercomparison exercises were inaugurated in 1991 at a workshop in Seattle, organized by John Hedges and John Farrington. Jonathan Sharp led further intercomparisons throughout the 1990s. These exercises were used to evaluate the various methods and to establish protocols for achieving agreement among laboratories. The intercomparison efforts evolved, with U.S. JGOFS encouragement, into a sustained reference material program (see sidebar) that currently provides water samples with agreed-upon DOC concentrations to analysts throughout the world.

The method intercomparisons provided two salient results. One, that the high DOC concentrations reported by Sugimura and Suzuki (1988) were not repeatable and therefore not valid. Two, the role of DOC in the carbon cycle remained enigmatic.

JGOFS investigators still faced certain critical questions: What is the true spatial and temporal variability of DOC in the ocean? What role does DOC have as a reservoir for carbon fixed during primary (and new) production? What role does DOC have in the biological pump? What aspects of its composition and character are important with regard to carbon cycling? Our best answers to these questions, reflecting the progress made to date, form the balance of this article.

We do not attempt a comprehensive review of recent findings on the role of DOM in ocean processes but focus instead on aspects of DOC that are most relevant to JGOFS questions. New areas and topics that we cannot cover here include the optical properties and biochemical composition of DOM, inclusion of DOM in models, the biological and chemical reactivity of DOM, and characteristics of DOM cycling in specific marine environments such as sediments, continental shelves, high latitudes and upwelling zones. Chapters in the forthcoming book mentioned above provide much greater detail on these topics.

\section{The Role of DOC in the Carbon Cycle}

Drawing on observations made at the U.S. JGOFS field study sites, we begin with an evaluation of the spatial distribution of DOC at regional and basin scales in both the surface and deep ocean. Next, we evaluate the temporal variability of DOC, focusing on seasonal variation in both high and low latitudes. Following this assessment of variability, we examine net community production, focusing on DOC that accumulates over time periods of biogeochemical relevance. In the section that follows, we evaluate the contribution of DOC to the biological pump by examining the mechanisms and locations of DOC export, and attempt to develop an understanding of the controls on export. We close providing some examples of how ideas about DOC have changed and discuss the significance of DOC's quality and character.

\section{Spatial Variability of DOC}

DOC is produced by biological processes in the upper ocean and mixed downward and diluted by physical processes. The upper-ocean distribution of DOC reflects the balance between these processes. 


\title{
Determining Dissolved Organic Carbon In The Ocean
}

\author{
Dennis A. Hansell \\ University of Miami \\ Miami, Florida USA
}

Dissolved organic matter in the ocean contains roughly the same amount of carbon as is present in the atmosphere in the form of carbon dioxide $\left(\mathrm{CO}_{2}\right)$. Ocean scientists from many nations are now studying the production, consumption, composition and distribution of this large pool of carbon with the aim of understanding its role in the ocean carbon cycle. Marine DOC measurements are made at more than 100 laboratories in the United States and many more elsewhere.

As the number of laboratories measuring dissolved organic carbon (DOC) began to increase in the early 1990s, it quickly became evident that poor agreement existed among the methods. The primary problem was the lack of commonly available seawater standards that could be employed for intercomparison of methods and results. To overcome this obstacle, the National Science Foundation (NSF) in 1998 began support for development of a reference material program for DOC analyses, administered by the Bermuda Biological Station for Research. The project has subsequently moved to the University of Miami.

Two forms of reference material have been developed for DOC analysis. One is deep ocean water (44-46 $\mu M$ DOC and 21.5 $\mu \mathrm{M}$ total nitrogen), collected at a depth of 2600 meters in the Sargasso Sea and containing biologically refractory DOC. The other is low carbon water, containing DOC at a level of roughly $2 \mu \mathrm{M}$. DOC concentrations for both materials are determined through the consensus of a group of independent investigators. Current participants are: James Bauer of Virginia Institute for Marine Science, Ronald Benner of the University of South Carolina, Yngve Børsheim of the Norwegian Institute of Science and Technology, Gus Cauwet of the Laboratoire Arago, France, Robert Chen of the University of Massachusetts, Boston, Dennis Hansell and Wenhao Chen of the University of Miami, Charles Hopkinson of the Marine Biological Laboratory, Ken Mopper and Jianguo Qian of Old Dominion University, and Hiroshi Ogawa of the University of Tokyo.

To date, some 45 laboratories in 18 nations have received more than 13,000 ampoules of these materials. Although the analytical protocols of these analysts vary greatly, their laboratories are now better able to achieve comparable results, a concrete step forward for ocean carbon-cycle research. Comparability extends and amplifies the value of all our individual efforts.

Concentrations are relatively high year round in the subtropical gyres (Figure 1). At high latitudes, where deep ocean water containing little DOC refreshes the surface layer in winter, DOC concentrations can be quite low. In coastal regions and along the equator, DOC values at the surface are normally relatively low where upwelling is strongest.

In the central equatorial Pacific, DOC is depressed at the surface because of upwelling (see the upward doming of the subsurface DOC contours at the equator [Figure 1]). The Equatorial Undercurrent, near $200 \mathrm{~m}$ west of the international dateline, has a DOC concentration around $55 \mu \mathrm{M}$. This water is transported eastward, shoaling to near surface levels in the central and eastern equatorial Pacific and bringing with it low DOC water (Figure 2). The return flow of surface water to the west shows an increase in DOC to roughly $65 \mu \mathrm{M}$ as a result of the biological processing of carbon.

The highest DOC concentrations $(>70 \mu \mathrm{M})$ are found in the Western Pacific Warm Pool west of $165^{\circ} \mathrm{W}$ in the upper $100 \mathrm{~m}$ (Figure 2). The position of the front separating the DOC-enriched warm pool to the west and the recently upwelled water to the east varies with the state of the El Niño-Southern Oscillation (ENSO) cycle. The DOC-enriched water is found further to the east during El Niño conditions.

The effect of upwelling on DOC concentrations is similar at coastal upwelling sites. Strong upwelling occurs along the coast of Oman in the Arabian Sea, driven by the intense winds of the Southwest Monsoon (Hansell and Peltzer, 1998). Low surface-water DOC concentrations are present during upwelling even when primary productivity is quite high, showing the effect of dilution from below.

Reports on the distribution and variability of DOC in the deep ocean have varied greatly over the years. Some authors have reported a complete absence of DOC gradients in the deep ocean; others have found small to very large gradients in concentration. In an effort to narrow the uncertainty, we surveyed representative sites in the deep ocean (Hansell and Carlson 1998a). As Figure 3 shows, we found a $29 \%$ decrease in DOC concentration from the northern North Atlantic ( $48 \mu \mathrm{M}$ in the Greenland Sea) to the northern North Pacific (34 $\mu \mathrm{M}$ in the Gulf of Alaska). This gradient reflects the export of formerly subtropical water 


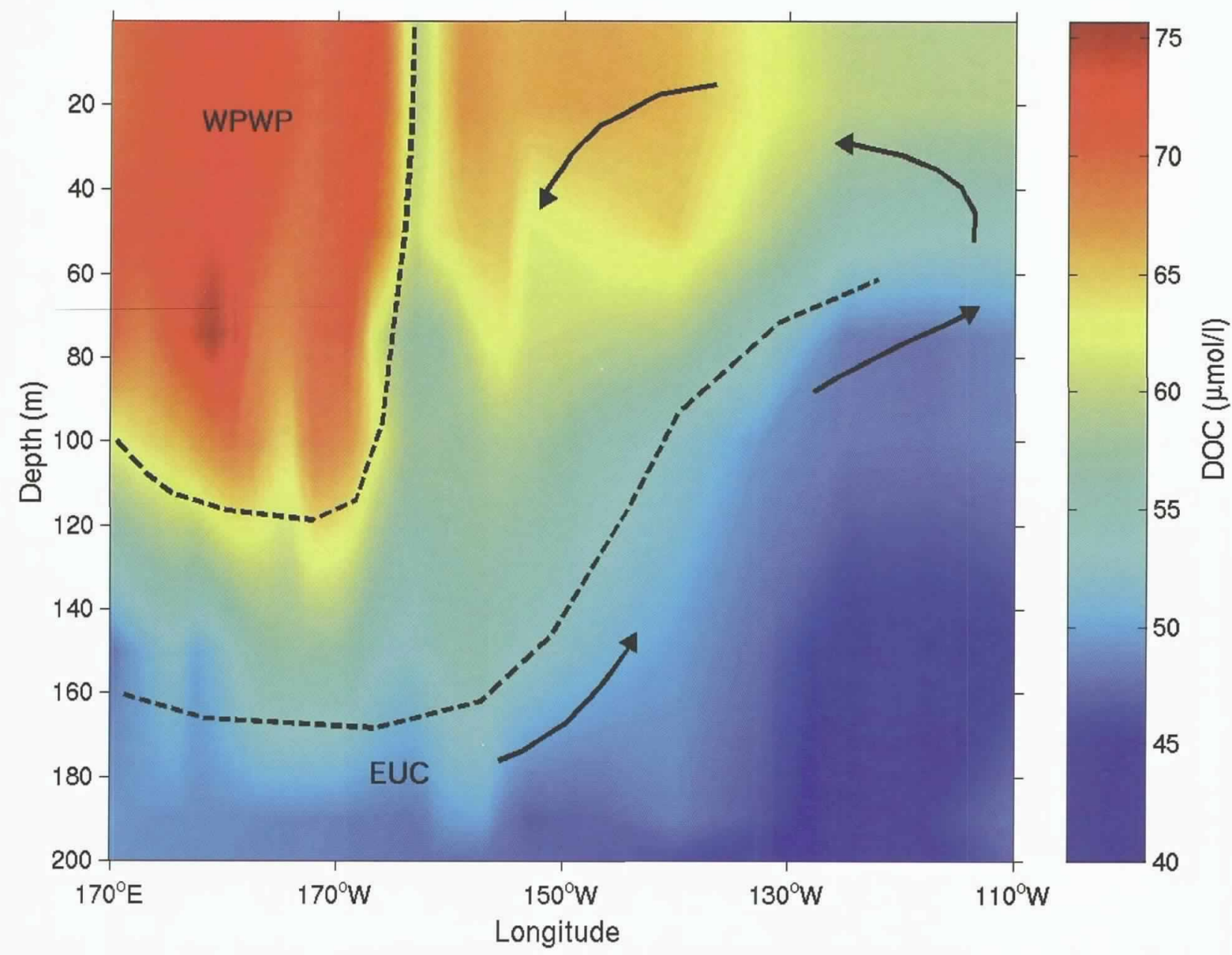

Figure 2. Zonal section of DOC along the equator in the Pacific Ocean. The data represent a compilation of measurements made in autumn 1992 (Peltzer and Hayward, 1996; 110 ${ }^{\circ} \mathrm{W}$ to $140^{\circ} \mathrm{W}$ ) and in autumn 1994 (Hansell et al., $1997 ; 150^{\circ} \mathrm{W}$ to $\left.170^{\circ} \mathrm{E}\right)$, during similar stages of the El Niño-Southern Oscillation cycle. Note the shoaling of Equatorial Undercurrent (EUC) water low in DOC concentration to the east. The high DOC concentrations west of the dateline are associated with the Western Pacific Warm Pool (WPWP). The dashed lines delineate the various water masses described; arrows indicate the general direction of relevant currents.

enriched in DOC, as North Atlantic Deep Water (NADW) is formed, and a decrease in DOC through microbial remineralization and mixing along the path of deep ocean circulation away from the North Atlantic. The formation of Antarctic Bottom Water (AABW) does not introduce significant additional DOC into the deep ocean; thus the concentrations remain low in the deep water near sites where AABW is formed.

\section{Temporal Variability of DOC}

Strong seasonal increases in DOC concentrations associated with phytoplankton blooms appear to be characteristic of systems that receive high inputs of new nutrients over winter periods. The waters of the Ross Sea polynya, for example, undergo deep mixing over the winter, with nitrate concentrations in excess of $30 \mu \mathrm{M}$ at the surface prior to the spring bloom. DOC concentrations increase in the surface layer from winter lows of $42 \mu \mathrm{M}$ to summer highs of 65-70 $\mu \mathrm{M}$ (Carlson et al., 2000). DOC concentrations in the Ross Sea increase by $15-30 \mu \mathrm{M}$ where the blooms of Phaeocystis and diatoms are particularly strong. Because DOC accumulation is concentrated within the upper 30 to 50 $\mathrm{m}$ in the Ross Sea, the change in integrated stocks of DOC in the upper $150 \mathrm{~m}$ is modest relative to the magnitude of primary production (up to $6 \mathrm{~g} \mathrm{C} \mathrm{m}^{-2} \mathrm{~d}^{-1}$ ). Where phytoplankton blooms are weak because of deep mixing or iron limitation, DOC concentrations remain low.

At the site of the U.S. JGOFS Bermuda Atlantic Time-series Study (BATS), located at $31^{\circ} 50^{\prime} \mathrm{N}, 64^{\circ} 10^{\prime} \mathrm{W}$ 
in the Sargasso Sea, convective overturning during winter introduces small amounts of new nutrients into the euphotic zone, followed by small phytoplankton blooms (see Karl et al., this issue). Adequate light is present in this subtropical region throughout the period when overturning occurs. Subsurface water low in DOC is mixed upward during the period of highest primary productivity, thereby reducing DOC concentrations in surface waters (Figure 4). Once stratification reasserts itself with the warming of the surface ocean and the bloom ends, DOC concentrations rebuild to normal summer levels. The change in concentration from the annual low to the annual high is only 3 to 6 $\mu \mathrm{M}$, small in comparison with the change in high-latitude systems. However, the bloom still supports a net production of as much as 1.5 moles $\mathrm{m}^{-2}$ of DOC over the upper $250 \mathrm{~m}$ (Carlson et al., 1994; Hansell and Carlson, 2001). Surprisingly, the annual increase in DOC stock is as large as in the much more productive Ross Sea (Carlson et al., 2000), but the increase in DOC concentration is less because the material is mixed more deeply into the water column during the period of net production.

$\mathrm{DOC}$ and bloom dynamics in the Arabian Sea during the Northeast Monsoon are similar to those of the Sargasso Sea. Convective overturn in the Arabian Sea, forced by cool dry winds off the Tibetan Plateau, mixes moderate amounts of nutrients into the euphotic zone. Similarly to the Sargasso Sea, changes in DOC concentration are not large during the bloom because of deep

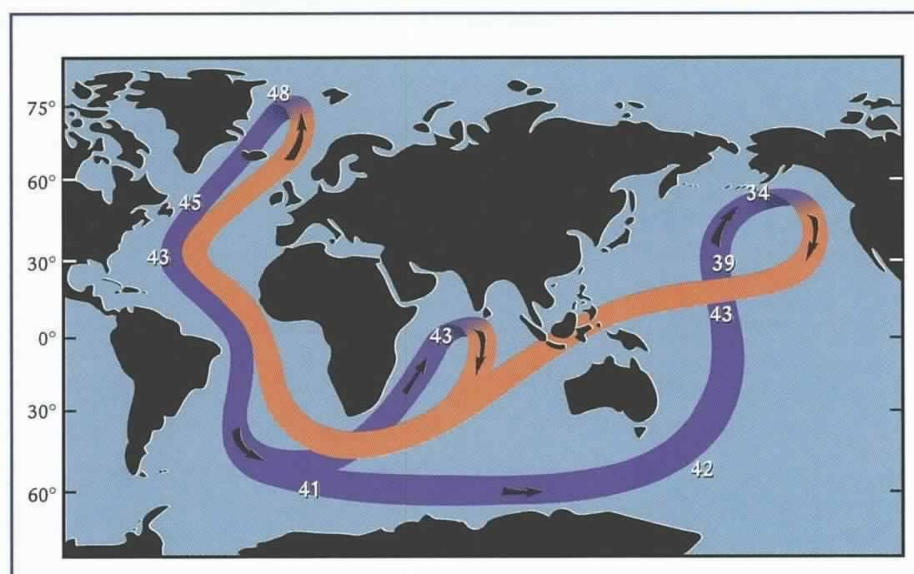

Figure 3. A global map of DOC concentrations in the deep ocean associated with the formation of deep water in the North Atlantic (orange arrows), its transport and distribution throughout the ocean (blue ribbon) and its return to the upper ocean (orange arrows). The North Atlantic near-surface concentration is assumed to be $60 \mu \mathrm{M}$ prior to overturning. Mixing and remineralization reduce DOC concentrations along the path of deep-water flow from $48 \mu \mathrm{M}$ in the Greenland Sea to a low of $34 \mu \mathrm{M}$ in the Gulf of Alaska. The cause of the large and abrupt decrease in DOC concentrations in the deep Pacific Ocean between the equator and the Gulf of Alaska is unknown. vertical mixing, but the DOC stock increases by 2 moles $\mathrm{C} \mathrm{m}^{-2}$ during the growing season (Hansell and Peltzer, 1998). Likewise, similar changes in DOC stock are characteristic of the Ross Sea.

Low-latitude systems do not experience winter freshening of the surface layer, nor exhibit seasonality in DOC concentrations. One example is the Hawaii Ocean Time-series (HOT) study site, located at $22^{\circ} 45^{\prime} \mathrm{N}$, $158^{\circ} \mathrm{W}$ in the North Pacific subtropical gyre. Variability in DOC occurs on interannual time scales at this location, but there is no recurring trend with seasons. Church et al. (2001) report interannual net accumulation from 1993 to 1999 of a DOM pool enriched in carbon and nitrogen relative to phosphorus. This longterm change may be a manifestation of the broad, ecosystem-wide shift from nitrogen to phosphorus limitation described by Karl et al. (this issue) for the region around the HOT site. On the other hand, only small shifts in DOM concentration have been noted in the Sargasso Sea.

\section{Net Community Production of DOC}

DOC is produced on a daily basis as part of primary and secondary production in the surface ocean. Most of the DOC released is remineralized by microorganisms on time scales of hours to days. For DOC to play a role in the ocean carbon cycle beyond serving as substrate for surface ocean microbes, it must act as a reservoir for carbon on the time scales of ocean circulation. The fundamental question is how much carbon fixed by primary producers accumulates each day or season in the DOC pool.

Seasonal increases of DOC stocks in the Ross Sea indicate that $8-20 \%$ of net community production (NCP) in the polynya accumulates each growing season as DOC (Carlson et al., 2000; Hansell and Carlson, 1998b). The balance of NCP is lost to the deep ocean as sinking biogenic particles, mostly in the form of the colonial phytoplankton Phaeocystis antarctica or diatoms. Average annual rates of NCP in the Ross Sea polynya range between 6 and 10 moles $C \mathrm{~m}^{-2}$; thus a maximal net DOC production of 1.2 to 2 moles $\mathrm{C} \mathrm{m}^{-2}$ occurs over the growing season. The rate of DOC production in the Ross Sea, normalized to NCP, is similar to that found in the equatorial Pacific. Estimates of net DOC production as a percentage of NCP in the central equatorial Pacific range from 6 to $40 \%$, with most estimates near the $20 \%$ level.

Net DOC production in the Ross Sea and the equatorial Pacific occurs when the conditions are right for net autotrophy. In the Ross Sea, these conditions are present when adequate vertical stability and light are available, while in the equatorial Pacific light becomes available following upwelling. At these sites, the vertical stability of the upper water column is relatively strong during the periods of net production. 


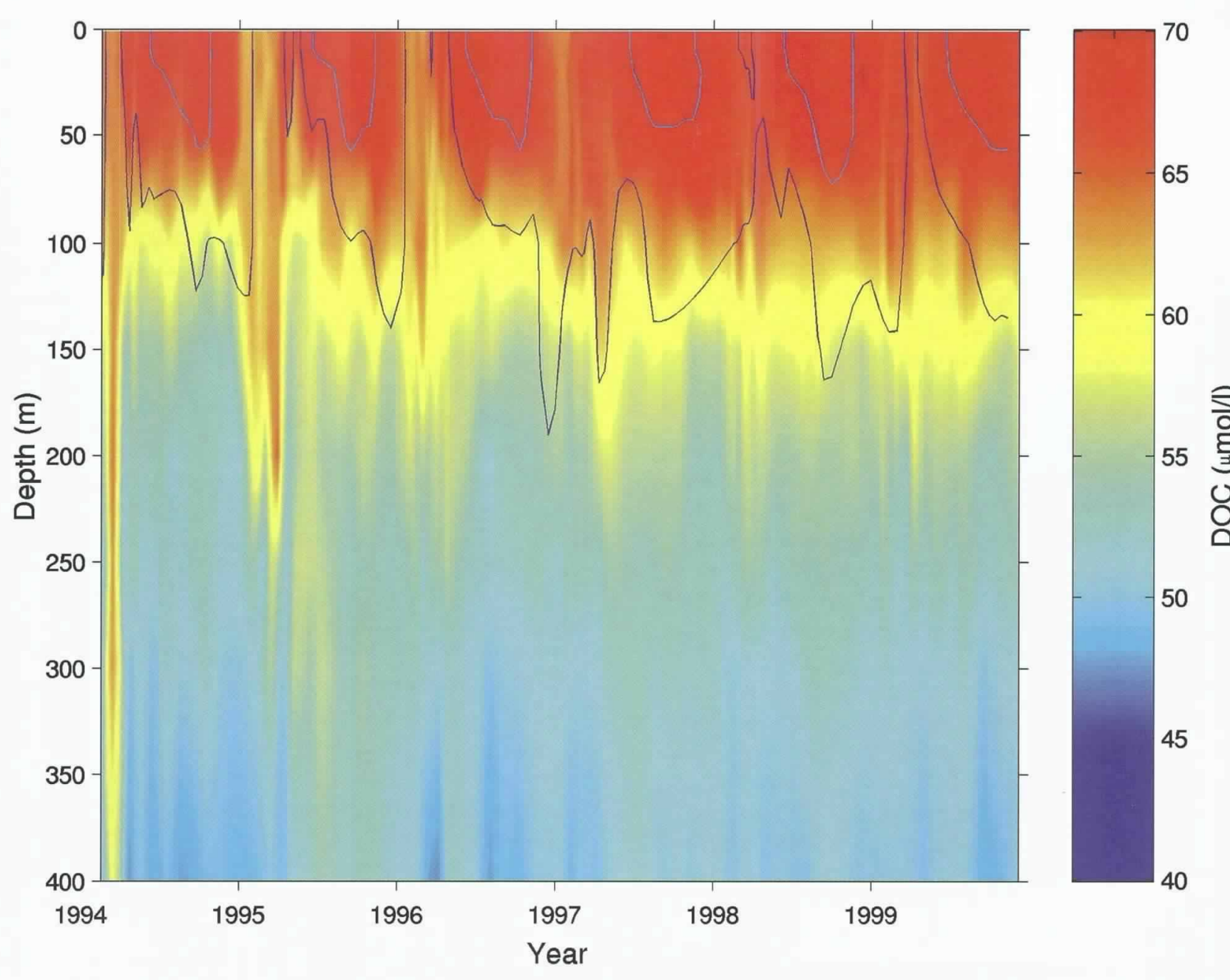

Figure 4. Time-series data on DOC concentrations in the western Sargasso Sea near Bermuda at the BATS site. Seasonality is evident in both the DOC and temperature contours (shallow contour is $24^{\circ} \mathrm{C}$; deeper contour is $20^{\circ} \mathrm{C}$ ). Note the decrease in surface DOC concentrations at the time of convective overturning. While concentrations decrease with this vertical mixing, the integrated stocks of DOC actually increase as a result of new primary production.

The Sargasso Sea presents a stark contrast. Light is adequate year round but nutrients are not, so that a reduction in vertical stability with convective overturn of the water column and entrainment of nutrients is required for net autotrophy to occur. In winter 1995 at the BATS site, the DOC stock increased by 1.4 moles C $\mathrm{m}^{-2}$ in response to maximum mixing depths of $260 \mathrm{~m}$ (Figure 4). In subsequent years with mixed layer depths of less than $220 \mathrm{~m}$, DOC stocks increased by less than 0.7 moles $\mathrm{C} \mathrm{m}^{-2}$ during overturning events (Hansell and Carlson, 2001). During the 1995 spring bloom, net DOC production was estimated to be $59-70 \%$ of the NCP (Hansell and Carlson, 1998b). This value declines to $8 \%$ when the period of evaluation is extended from the seasonal spring bloom to the entire year.

One benefit of normalizing DOC accumulation rates to NCP is that we have a lot of data on NCP. We can use the findings on net DOC production, along with existing estimates for new (nitrate-based) production in various ocean regions, to estimate annual rates of DOC accumulation (Hansell and Carlson, 1998b). As one would expect, the regions of highest new production, such as equatorial and coastal upwelling areas, contribute the most to net DOC production globally. The weakest sites for the entrainment of nitrate to the surface, such as the subtropical gyres, contribute the least to net DOC production. About $17 \%$ of global new production each year ends up as net DOC production. If global new production is roughly $7 \times 10^{15} \mathrm{~g} \mathrm{C} \mathrm{yr}^{-1}$, we calculate that net DOC production in the global ocean should be about $1.2 \times 10^{15} \mathrm{~g} \mathrm{C} \mathrm{yr}^{-1}$.

\section{The Contribution of DOC to the Biological Pump}

The vertical export of organic matter from the surface ocean into deeper waters, often referred to as the 
"biological pump", is a central process in the ocean carbon cycle (see Ducklow et al., this issue). The export of sinking biogenic particles drives respiration in the ocean interior and helps to maintain the strong vertical gradient of inorganic carbon in the ocean. Prior to the JGOF years, the role of DOC as a component of export received little analysis beyond speculative modeling. DOC arguably plays its most important role in the ocean carbon cycle if and when it contributes to the biological pump.

DOC export in the ocean is a result of accumulation in the surface ocean (Figure 1), redistribution with the wind-driven circulation, and eventual transport to depth with overturning (thermohaline) circulation at high latitudes and subduction in the subtropical gyres. DOC export with the ventilation of the ocean occurs when there is a vertical gradient in DOC concentrations at the onset of overturning. When vertical DOC gradients are weak or absent, there is little net downward movement of DOC with overturning.

Establishing the contribution of DOC to the export of carbon from the surface ocean is best undertaken by normalizing the gradients in DOC concentrations to the gradients in Apparent Oxygen Utilization (AOU). AOU is associated with the remineralization of sinking biogenic particles and subducted DOC and reflects the total oxidation of biogenic carbon along specific density layers. In the isopycnal surfaces between 23.5 and 27.0 sigma-theta (a unit of density) along $170^{\circ} \mathrm{W}$ in the South Pacific, $21 \%$ to $47 \%$ of the AOU is driven by the oxidation of DOC (Doval and Hansell, 2000). DOC oxidation along $170^{\circ} \mathrm{W}$ is largely restricted to the upper $500 \mathrm{~m}$. At greater depths, only biologically refractory DOC remains in the water column; thus oxidation of sinking organic particles alone drives AOU at these depths.

Carbon fixed in DOC is sequestered from exchange with the atmosphere for the longest periods of time when export is associated with the formation of deep and bottom water. The strong meridional gradient in deep water DOC, along the proximal path of the deep western boundary current, provides evidence for the export of DOC with NADW formation (Figure 3; Hansell and Carlson, 1998a). NADW, with an initial DOC concentration of $48 \mu \mathrm{M}$ in the deep Greenland Sea, overrides and entrains northward flowing AABW with a DOC concentration of $41 \mu \mathrm{M}$. The mixing of these two source waters, along with microbial degradation of the labile DOC fractions, produces a concentration gradient in the Atlantic Ocean (Figure 3).

AABW forms in the cyclonic gyres that develop south of the Antarctic Circumpolar Current, particularly those in the Weddell and Ross Seas. The contribution of AABW formation to DOC export appears to be very small. Studies in the Ross Sea during the 1997 austral summer season showed that DOC concentrations in the surface $50 \mathrm{~m}$ rose more than $20 \mu \mathrm{M}$ above background levels in certain areas (Carlson et al., 2000). By the time winter overturning began in the fall, reminer- alization of the DOC reduced mean concentrations to less than $5 \mu \mathrm{M}$ above background. The vertical export of this material, if any remains after overturning is complete, would contribute only $2 \%$ of the total annual export of particulate plus dissolved organic carbon in the Ross Sea. Remineralization of the DOC prior to overturning prevents it from making a major contribution to export in this system.

In order for DOC export to occur, its concentration must be higher at the surface than in deeper waters. The excess DOC in surface waters consists of fractions that are resistant to rapid microbial degradation. We use the term "exportable DOC" to refer to DOC in surface waters during overturning that is in excess of concentrations at the depth to which vertical mixing takes place. Because the lifetime of exportable DOC is longer than the season of production, it is available for transport via surface currents to sites where water masses are formed.

DOC is produced primarily in the equatorial and coastal upwelling regions, and secondarily in the subtropical gyres (Hansell and Carlson, 1998b). We hypothesize that the DOC produced at these sites accumulates in the subtropical gyres (Figure 5). Wind-driven circulation patterns in the surface ocean dictate the transport and distribution of the accumulated DOC. When DOC-enriched surface waters from the gyres are transported to higher latitudes, DOC is exported with overturning circulation.

The high-latitude regions replenished by subtropical gyre waters via western boundary currents, such as the northern North Pacific and northern North Atlantic, contain exportable DOC during the times when overturning takes place. DOC export occurs in high-density water masses, such as the NADW, the North Pacific Intermediate Water and probably the Labrador Sea Intermediate Water; water masses that are formed in high northern latitudes and fed by subtropical water.

The Southern Ocean, on the other hand, does not appear to contain significant amounts of exportable DOC. Sharp fronts in a variety of properties separate the Antarctic Circumpolar Current System (ACCS) from the DOC-enriched subtropical gyres (Figure 5), as evidenced by the abrupt shifts in DOC concentrations south of the gyres shown in Figure 1. Locally produced exportable DOC is absent as well (Carlson et al., 2000). Thus DOC export in high-density water masses formed in the high latitudes of the Southern Hemisphere is relatively weak.

\section{Changing Ideas on DOC and the Carbon Cycle}

One axiom of our understanding about DOC has been that nutrient depletion drives high rates of net production. This perception is based on numerous batch phytoplankton culture experiments, where nutrients were allowed to run out. When nutrients were present and the phytoplankton were in exponential growth phase, DOC release was very small. When 
nutrients were depleted and the plants went into stationary phase, carbon fixation exceeded the nitrogen stocks available to support biomass growth and carbon-rich DOM was released. Because of these results, the assumption has been that nutrient depletion forces high levels of DOC production everywhere in the ocean. It would follow that high levels of DOC would be present in oligotrophic systems because of nutrient limitation.

This argument concerning oligotrophic systems can be tested against BATS timeseries data from the Sargasso Sea (Figure 4). Net DOC production takes place primarily when rates of primary production are highest during the spring bloom period. During summers, when nutrients are most depleted, no further accumulation of DOC takes place. Nor is there a major increase in bacterial respiration rates relative to primary productivity to indicate an increased release of labile DOC.

The data from the Sargasso Sea indicate that nutrient depletion alone does not drive high rates of DOC production. Once nutrient depletion is sustained in natural systems, a new equilibrium state is eventually achieved with a different plankton community structure. Perhaps it is the rapid switch in nutrient levels from abundance to depletion that triggers rapid DOC production in experimental cultures. If this is the case, transient events should be the most important for rapid DOC production.

Because of the role of stratification in maintaining elevated DOC levels in the surface ocean, a positive correlation between DOC concentration and primary productivity is absent for much of the oligotrophic ocean. In the highly stratified portions of the open ocean, DOC is instead positively correlated with temperature, another sign of the importance of physical controls on ecosystem processes. In contrast, at higher latitudes where DOC concentrations are depressed during the winter, increases in DOC do indeed accompany the springtime rise in primary productivity (Carlson et al., 2000). In these high-latitude systems, increased water column stability favors both phytoplankton growth and DOC accumulation in the upper ocean.

\section{The Effect of DOC Quality on Carbon Export}

Over the last decade, investigators have made great advances in understanding the significance of DOM lability (bio- logical availability) and how it varies in space and time. By combining information on the age of DOC from ${ }^{14} \mathrm{C}$ measurements with data from utilization experiments and accurate determinations of distribution, we have gained insights into the partitioning of the bulk DOC pool into various fractions defined by their lability.

Ocean ecosystems below the euphotic zone are characterized by net heterotrophy. Biologically labile DOC delivered to these depths by diffusion, turbulent mixing or the dissolution of sinking particles is utilized

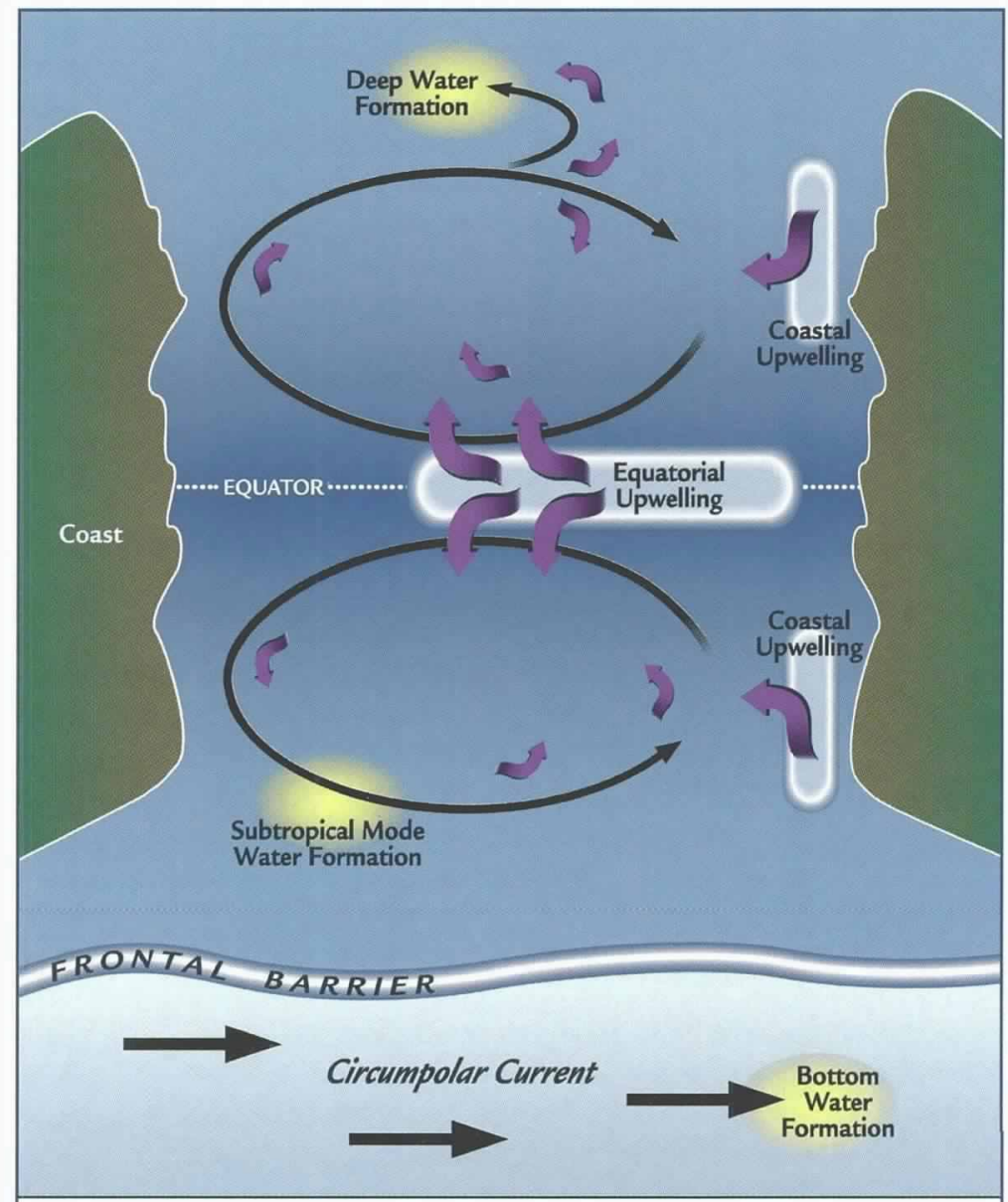

Figure 5. DOC net production, transport and export in the ocean. Regions of significant net DOC production (broad arrows) include coastal and equatorial upwelling regions that support much of the global new production. DOC is transported into and around the subtropical gyres with the wind-driven surface circulation. Export takes place if exportable DOC (elevated concentrations indicated by dark blue fields) is present during overturning of the water column. Such is the case when DOC-enriched subtropical water serves as a precursor for deep and intermediate water mass formation. DOC is also exported with subduction in the gyres. In regions where DOCenriched subtropical water is prevented by polar frontal systems from serving as a precursor for overturning circulation (such as at the sites of Antarctic Bottom Water formation in the Southern Ocean) DOC export is a weak component of the biological pump. Waters south of the Antarctic Polar Front lack significant exportable DOC (depicted by light blue field) during winter. 
by microbes, leaving behind an increasingly refractory remnant. The refractory pool of DOC is best represented by the deep ocean stocks ( $>1000 \mathrm{~m}$ ) with apparent mean ages of 4000 to 6000 years in the North Atlantic and the North Central Pacific oceans (Bauer et al., 1992). Because the mean age of the deep DOC is much greater than the time scale of thermohaline circulation, refractory DOC is reintroduced into surface waters via ocean circulation.

Upper ocean stocks of DOM in excess of the deep refractory pool are composed of "labile" and "semilabile" fractions. Labile compounds, such as neutral sugars and amino acids, fuel rapid microbial production turnover on time scales of minutes to days; they are generally present at nanomolar concentrations. Because labile compounds represent a very small fraction of bulk DOM in the open ocean (0-6\%), the vertical gradient of the bulk DOM observed in thermally stratified systems mostly comprises semi-labile DOM. The semi-labile fraction is made up of polysaccharides (Benner et al., 1992) and is biologically reactive over months to years. Thus it accumulates in surface waters and generates the vertical gradients of DOC that we observe. This fraction, referred to above as exportable DOC, contributes to export if it escapes microbial degradation in the surface waters long enough to be mixed into the depths during winter overturning (Carlson et al., 1994).

\section{Conclusions}

JGOFS brought new and exciting questions to ocean biogeochemistry, and the scientific community responded with persistence and zeal. Advancing our understanding of the marine carbon cycle required significant improvements in our methodologies and protocols. We relearned the value of reference materials, intercomparisons and coordinated efforts for attacking large and difficult questions.

Investigators interested in DOC have made a good deal of progress during the JGOFS years. As with all good science, much has been learned, however many new questions have also been generated. We have more to learn about what limits the amount of DOC in the ocean, what controls its production and lifetime, and what DOC is composed of. The amount of carbon residing in the pool of DOC in the ocean is equivalent to the amount in the pool of atmospheric $\mathrm{CO}_{2}$. Thus a small change in the size of the DOC pool could have a major effect on the air-sea exchange of carbon. A fuller understanding of the role of DOC in the ocean carbon cycle and how it might respond to environmental perturbation is essential to our ability to predict the effects of changing climate on the global ocean.

This is U.S. JGOFS Contribution Number 681.

\section{References}

Bauer, J.E., P.M. Williams and E.R.M. Druffel, 1992: ${ }^{14} \mathrm{C}$ activity of dissolved organic carbon fractions in the north-central Pacific and Sargasso Sea. Nature, 357, 667-670.

Benner, R., J.D. Pakulski, M. McCarthy, J.I. Hedges and P.G. Hatcher, 1992: Bulk chemical characteristics of dissolved organic matter in the ocean. Science, 255, 1561-1564.

Carlson, C.A., H.W. Ducklow and A.F. Michaels, 1994: Annual flux of dissolved organic carbon from the euphotic zone in the northwestern Sargasso Sea. Nature, 371, 405-408.

Carlson, C.A., D.A. Hansell, E.T. Peltzer and W.O. Smith, Jr., 2000: Stocks and dynamics of dissolved and particulate organic matter in the southern Ross Sea, Antarctica. Deep-Sea Res. II, 47, 3201-3225.

Church, M.J., H.W. Ducklow and D.M. Karl, 2002: Decade-scale secular increase in dissolved organic carbon and nitrogen inventories in the North Pacific subtropical gyre. Limn and Oceano, 47[1], 1-10.

Doval, M. and D.A. Hansell, 2000: Organic carbon and apparent oxygen utilization in the western South Pacific and central Indian Oceans. Marine Chemistry, 68, 249-264.

Hansell, D.A., C.A. Carlson, N. Bates and A. Poisson, 1997: Horizontal and vertical removal of organic carbon in the equatorial Pacific Ocean: A mass balance assessment. Deep-Sea Res. II, 44, 2115-2130.

Hansell, D.A. and C.A. Carlson, 1998a: Deep ocean gradients in dissolved organic carbon concentrations. Nature, 395, 263-266.

Hansell, D.A. and C.A. Carlson, 1998b: Net community production of dissolved organic carbon. Global Biogeochem. Cycles, 12, 443-453.

Hansell, D.A. and C.A. Carlson, 2001: Biogeochemistry of total organic carbon and nitrogen in the Sargasso Sea: Control by convective overturn. Deep-Sea Res. II, 48, 1649-1667.

Hansell, D.A. and E.T. Peltzer, 1998: Spatial and temporal variations of total organic carbon in the Arabian Sea. Deep-Sea Res. II, 45, 2171-2193.

Peltzer, E.T. and N.A. Hayward, 1996: Spatial and temporal variability of total organic carbon along $140^{\circ} \mathrm{W}$ in the equatorial Pacific Ocean in 1992. DeepSea Res. II, 43, 1155-1180.

Sugimura, Y. and Y. Suzuki, 1988: A high-temperature catalytic oxidation method for the determination of non-volatile dissolved organic carbon in seawater by direct injection of a liquid sample. Mar. Chem., 24, 105-131.

Suzuki, Y., Y. Sugimura and T. Itoh, 1985: A catalytic oxidation method for the determination of total nitrogen dissolved in seawater. Mar. Chem., 16, 83-97.

Williams, P.M. and E.R.M. Druffel, 1988: Dissolved organic matter in the ocean: Comments on a controversy. Oceanography, 1, 14-17. 